\title{
Nuclear Morphometric Study in Different Thyroid Lesions
}

\author{
Hend S.A. Abo Safia ${ }^{*}$, Samir N. Mina, Zeinab M.K. El-Guindy, \\ Omnia M.K. Rizk and Dareen A.M. Ali \\ Pathology Department, Faculty of Medicine, Tanta University, Egypt \\ *Corresponding author
}

\begin{abstract}
A B S T R A C T

\begin{tabular}{|l|}
\hline Ke y w o r d s \\
Papillary thyroid \\
carcinoma, PDTC, \\
Nuclear morphometry, \\
Mean nuclear area, \\
Nuclear perimeter, \\
Maximal nuclear \\
diameter
\end{tabular}

Thyroid diseases are common in the general population and usually presented as thyroid nodules. Most nodules are benign while thyroid cancer represents 5-24\% of cases. Thyroid carcinoma is classified into PTC, FTC, ATC, and MTC. The aim of this study was to assess the role of morphometric study in the differentiation between benign and malignant thyroid lesions. Nuclear morphometry measurement was carried out on 90 different thyroid lesions (40 benign and 50 malignant). Morphometry was performed using 3 parameters (mean nuclear area, nuclear perimeter and maximal nuclear diameter). All 3 measured parameters were statistically significant as they were much higher in malignant lesions than benign lesions. Also, statistically significant correlation was found between follicular adenoma, FVPTC and follicular carcinoma. In benign lesions, Granulomatous thyroiditis had the lowest nuclear morphometric parameters while Hurthle cell adenoma had the highest parameters. Inn malignant tumors, PDTC and medullary carcinoma had the lowest measured parameters while anaplastic thyroid carcinoma had the highest. Nuclear morphometric measurements can aid in the differentiation between benign and malignant thyroid lesions especially follicular patterned lesions.
\end{abstract}

\section{Introduction}

Thyroid diseases are extremely common in the general population. They are usually presented as thyroid nodules and discovered during routine medical care. It is estimated that up to $7 \%$ of the general population develops clinically palpable thyroid nodules (Gharib et al., 2010).

Most of thyroid nodules are benign, while malignant thyroid tumors represents only 5$24 \%$ of cases. However, there is increase in thyroid cancer incidence in the last 30 years
(Colonna et al., 2010) and (Cătană et al., 2012). Thyroid carcinoma is the most common malignancy of the endocrine system (Ozolins et al., 2012). According to Egyptian National Cancer Institute, thyroid carcinoma constituted a majority of $65.31 \%$ of endocrine malignant tumors. The most common malignant tumor of thyroid gland is papillary carcinoma accounting for $67.6 \%$ (Mokhtar et al., 2007).

Papillary thyroid carcinoma (PTC) is the most common type of thyroid malignancy $(85 \%)$ and it is characterized by a special set of nuclear features. It is characterized by slow 
growth and an excellent prognosis. However, some cases show relatively early recurrence, severe invasion, lymph node metastasis (LNM), or distant metastasis. It is very important to specify the characteristics of PTC that have a high risk for invasion and distant metastasis (Rossi et al., 2013).

Follicular carcinoma represents $10-15 \%$ of thyroid cancer but the diagnosis is one of the most difficult topics in thyroid pathology, because the criteria are determined only by capsular and/or vascular invasion of the tumor, and these histological features may be equivocally presented in the conventional histological sections (Buehler et al., 2013).

Computerized nuclear morphometry is an objective computer assisted image analysis method to estimate the chosen parameters in every individual cell. Its potential diagnostic role in differentiation between benign and malignant tumors has been investigated in many other tumors. The wide application of computerized morphometry in histopathology of thyroid follicular neoplasms is becoming essential due to the difficulty in identification between malignant follicular cells from adjacent normal follicular cells on conventional cytology (Priya and Sundaram 2011).

Nuclear morphometric study is a useful tool in the assessment of some tumors and can provide reliable parameters for diagnosis and prognosis. For example, in GIT and breast epithelial tumors, nuclear morphometry can assess the predictors of progression and help in differentiating benign from malignant entities (Shih et al., 2012).

\section{Materials and Methods}

This retrospective study was carried out on 90 paraffin blocks ( 25 males and 65 females, age ranged between $20-70 y e a r s)$, collected from archive of Pathology department, Faculty of Medicine, during the period from August 2015 to May 2017. Approval from research ethics committee (REC), Faculty of Medicine, was taken antecedent to conducting study.

\section{Histopathological study}

Serial sections were prepared from each block. Histologicalsections, 4-mm thick, were stained by hematoxylin and eosin (H\&E) for histopathological and nuclear morphometric study of different thyroid lesions. The studied H\&E sections were reviewed.

\section{Nuclear morphometry}

The morphometric analysis was performed at the Pathology Department, National Research Center using the Leica Qwin 500 Image Analyzer (LEICA Imaging Systems Ltd, Cambridge, England,) which consists of Leica DM-LB microscope with JVC color video camera attached to a computer system Leica Q $500 \mathrm{IW}$.

The morphometric analysis is carried out on H\&E stained slides. From selected areas, 10 fields at magnification $\times 400$ were captured in each case measuring area (expressed in um2) and area percentage of intact nuclei of thyroid follicle. Also 10 nuclear morphometric parameter were estimated (expressed in um). The results appear automatically on the monitor in the form of area, area fraction ad area percentage. Parameter of nuclei appears automatically as diameter or perimeter and maximum, minimum reading.

\section{Statistical analysis}

Database and data analyses were done with IBM SPSS Statistics 20. Descriptive and analytical methods were used. For comparison of variables, parametric ( $\mathrm{t}$ test, ANOVA) and non-parametric tests (chi square, Mann 
Whitney U test, Kruskal Wallis test) were employed. With objective to compare markers Receiver Operating Curve (ROC) was constructed. Sensitivity, specificity, positive and negative predictive values, and diagnostic odds ratio were calculated for single and combination of markers in program MedCalc $®$ (Version 10.2.0.0).

Probability values less than 0.05 were considered statistically significant.

\section{Results and Discussion}

Histopathological results of the studied cases

Histopathological examination of the studied cases was done to reevaluate the pathological diagnosis.

It revealed that; forty cases were benign thyroid lesions and fifty cases were malignant thyroid lesions.

\section{Benign thyroid lesions}

Forty cases were benign thyroid lesions, ten cases of these benign lesions were hyperplastic thyroid nodules (three of them were toxic nodules), ten cases were Hashimoto's thyroiditis, five cases were granulomatous thyroiditis and ten cases were thyroid adenoma figure 1, five cases were Hurthle cell adenoma.

\section{Malignant thyroid tumors}

Fifty cases were malignant thyroid lesions. Fifteen cases of these malignant lesions were papillary carcinoma figure 2, 10 cases were follicular carcinoma, 7 cases were poorly differentiated carcinoma figure 3, 10 cases were undifferentiated thyroid carcinoma, and 8 cases were medullary thyroid carcinoma. Nuclear morphometry results

\section{Mean Nuclear area}

Among benign thyroid lesions, granulomatous thyroiditis had the lowest MNA (2.10 um2) while Hurthle cell adenoma had the highest (MNA 32.86 um2) table 1 and figure 4. Among malignant cases, anaplastic carcinoma had recorded the highest MNA (46.55um2) and PDTC had the lowest MNA (15 um2) table 2 and figure 5.

\section{Nuclear perimeter}

Among benign cases, granulomatous thyroiditis was found to have the lowest nuclear perimeter (5.57 um) while Hurthle cell adenoma had the highest nuclear perimeter (21.96 um) table 1. Among malignant cases insular carcinoma has recorded the lowest nuclear perimeter (14.49 um), while anaplastic carcinoma cases were found to have the highest nuclear perimeter $(25.18 \mathrm{um})$ table 2 .

\section{Maximal nuclear diameter}

Granulomatous thyroiditis was found to have the lowest diameter (1.62um) while Hurthle cell adenoma recorded the highest diameter (5.59 um) among benign studied cases table 1 and figure 6 . Among malignant cases medullary thyroid carcinoma was found to have the lowest nuclear diameter (2.15um) while anaplastic thyroid carcinoma had the highest diameter $(8.03 \mathrm{um})$ table 2 and figure 7.

Role of nuclear morphometric study in differentiation between follicular neoplasms

\section{Mean nuclear area in follicular patterned thyroid neoplasia (Table 3)}

On comparison between follicular adenoma, follicular carcinoma and FVPTC; statistically significant difference was found between 
them. As the $\mathrm{P}$ value was $0.001 *$ between follicular adenoma \& FVPTC and 0.001* between adenoma \& follicular carcinoma and 0.005* between FVPTC \& Follicular carcinoma.

\section{Nuclear perimeter in follicular patterned thyroid neoplasia (Table 4)}

On comparison between follicular adenoma, follicular carcinoma and FVPTC in the current work, statistically significant difference was found between them regarding nuclear perimeter indicating that it can be used for differentiation between these lesions. It was found that the $\mathrm{P}$ value was $0.014 *$ between adenoma \& FVPTC and 0.001* between Adenoma \& follicular carcinoma and $0.002 *$ between FVPTC \& Follicular carcinoma.

\section{Maximal nuclear diameter in follicular patterned thyroid neoplasia (Table 5)}

On comparison between follicular adenoma, follicular carcinoma and FVPTC in the current work, statistically significant difference was found between them regarding maximal nuclear diameter indicating that it can be used for differentiation between these lesions. It was observed that the $\mathrm{P}$ value was $0.005^{*}$ between adenoma \& FVPTC and 0.001* between adenoma \& follicular carcinoma and 0.001* between FVPTC \& Follicular carcinoma.

Malignant thyroid tumorsare the most prevalent endocrine malignancy accounting for $1 \%$ of all cancers worldwide. It is more common in females about three to four times higher than males. It is the sixth most common malignancy diagnosed in women (Guerra et al., 2013).

In the current study nuclear morphometric measurement was done on both studied thyroid lesions (benign and malignant). The evaluated measurements were the mean nuclear area, nuclear perimeter and maximal nuclear diameter.

Regarding the mean nuclear area in benign lesions, granulomatous thyroiditis had the lowest MNA while Hurthle cell adenoma had the highest MNA. Meanwhile, the mean nuclear area in the studied malignant group was highest in anaplastic carcinomas while PDTC carcinoma had the lowest MNA with a statistically significant correlation.

These results are similar to the results of Abdel Maksoud et al., (2013) who detected a statistically significant correlation between MNA and type of thyroid tumor. Also they concluded that benign lesions had a significantly lower MNA compared with malignant ones. In a study conducted by Dey and Saikia, (2011), the MNA of PDTC was higher than that of the current results as they worked on FNA cytology specimens, but the MNA for the studied follicular carcinoma was in agreement with the results of the current study.

Aiad et al., (2009) reported that they excluded cases of oncocytic neoplasms from their study because they constitute distinct entities. In the current study, cases of Hurthle cell adenoma reported the highest morphometric measurement among the studied benign lesions.

On comparison between follicular adenoma, follicular carcinoma and FVPTC in the current work, statistically significant correlation was found between them regarding MNA indicating that MNA can be used for differentiation between these lesions with significant $\mathrm{P}$ values. These findings are close to those of Bakr et al., (2000) who reported that the MNA is a statistically significant discriminator between thyroid carcinomas and adenomas. 
Table.1 MNA, NP and MND in benign cases

\begin{tabular}{|c|c|c|c|}
\hline Benign & MNA & Perimeters & diameter \\
\hline Hyperplastic thyroid nodule & $12.11 \pm 3.80$ & $13.41 \pm 1.92$ & $4.37 \pm 0.57$ \\
Toxic nodule & $28.41 \pm 8.04$ & $19.71 \pm 2.61$ & $5.05 \pm 0.63$ \\
Hashimoto thyroiditis & $17.63 \pm 2.44$ & $15.71 \pm 0.95$ & $4.31 \pm 0.89$ \\
Granulomatous thyroiditis & $2.10 \pm 0.67$ & $5.57 \pm 0.82$ & $1.62 \pm 0.33$ \\
Follicular Adenoma & $14.78 \pm 2.87$ & $14.42 \pm 1.45$ & $4.34 \pm 0.41$ \\
Hurthle cell adenoma & $32.86 \pm 7.34$ & $21.96 \pm 2.54$ & $5.59 \pm 0.68$ \\
\hline F. test & 138.771 & 253.694 & $\mathbf{1 3 8 . 4 8 9}$ \\
\hline P value & $\mathbf{0 . 0 0 1 *}$ & $0.001 *$ & $0.001 *$ \\
\hline
\end{tabular}

Table.2 MNA, NP and MND in malignant cases

\begin{tabular}{|c|c|c|c|}
\hline Malignant & MNA & Perimeter & Diameter \\
\hline Papillary carcinoma & $30.98 \pm 7.77$ & $21.33 \pm 3.82$ & $\mathbf{6 . 2 1} \pm \mathbf{1 . 1 6}$ \\
FVPTC & $22.23 \pm 5.14$ & $17.51 \pm 2.07$ & $\mathbf{5 . 2 6} \pm \mathbf{0 . 8 2}$ \\
Follicular carcinoma & $36.30 \pm 11.15$ & $22.47 \pm 3.39$ & $7.26 \pm 1.33$ \\
PDTC & $15.00 \pm 4.71$ & $14.49 \pm 2.29$ & $4.77 \pm 0.63$ \\
Anaplastic carcinoma & $46.55 \pm 18.45$ & $25.18 \pm 4.85$ & $\mathbf{8 . 0 3} \pm 1.61$ \\
Medullary carcinoma & $18.85 \pm 4.02$ & $16.48 \pm 1.77$ & $\mathbf{2 . 1 5} \pm 0.39$ \\
\hline F. test & 48.820 & 52.136 & $\mathbf{1 8 1 . 5 2 3}$ \\
\hline P value & $\mathbf{0 . 0 0 1 *}$ & $0.001 *$ & $0.001 *$ \\
\hline
\end{tabular}

Table.3 Correlation between the MNA of FA, FVPTC and FC

\begin{tabular}{|c|c|c|c|}
\hline Area & Adenoma & FVPTC & Follicular carcinoma \\
\hline Range & $11.62-17.27$ & $14.25-34.47$ & $17.38-64.95$ \\
\hline Mean \pm SD & $14.46 \pm 2.87$ & $22.23 \pm 5.14$ & $36.30 \pm 11.15$ \\
\hline T. test & & 138.489 \\
\hline p. value & \multicolumn{3}{|c|}{\begin{tabular}{c} 
\\
\hline Adenoma \&FVPTC
\end{tabular} Adenoma \& FC $^{*} 0.001^{*}$} \\
\hline $0.001^{*}$ & $0.001^{*}$ & & $0.005^{*}$ \\
\hline
\end{tabular}

Table.4 Correlation between FA, FVPTC and FC regarding nuclear perimeter

\begin{tabular}{|c|c|c|c|}
\hline Perimeter & Adenoma & FVPTC & FC \\
\hline Range & $9.9-21.12$ & $13.84-23.34$ & $15.91-29.88$ \\
\hline Mean \pm SD & $14.42 \pm 1.44$ & $17.50 \pm 2.07$ & $22.47 \pm 3.39$ \\
\hline T. test & & 138.489 \\
\hline p. value & & $0.001^{*}$ \\
\hline Adenoma \&FVPTC & Adenoma \& FC & FVPTC\&C F \\
\hline $\mathbf{0 . 0 1 4} *$ & $0.001^{*}$ & \multicolumn{3}{|c|}{$0.002^{*}$} \\
\hline
\end{tabular}


Table.5 Correlation between FA, FVPTC and FC regarding maximal nuclear diameter

\begin{tabular}{|c|c|c|c|}
\hline Diameter & $\begin{array}{c}\text { Follicular } \\
\text { Adenoma }\end{array}$ & FVPTC & $\begin{array}{c}\text { Follicular } \\
\text { carcinoma }\end{array}$ \\
\hline Range & $3.55-5.24$ & $4.21-7.6$ & $5.58-10.29$ \\
\hline Mean \pm SD & $4.34 \pm 0.41$ & $5.26 \pm 0.82$ & $7.26 \pm 1.33$ \\
\hline T. test & \multicolumn{3}{|c|}{138.489} \\
\hline p. value & \multicolumn{3}{|c}{$0.001^{*}$} \\
\hline Adenoma \&FVPTC & Adenoma \& FC & FVPTC\& FC \\
\hline $\mathbf{0 . 0 0 5}^{*}$ & $0.001^{*}$ & & $0.001^{*}$ \\
\hline
\end{tabular}

Fig.1 A case of microfollicular adenoma surrounded by thin fibrous capsule and composed of small follicles which compress normal thyroid tissue outside the capsule [H\&E, x200]

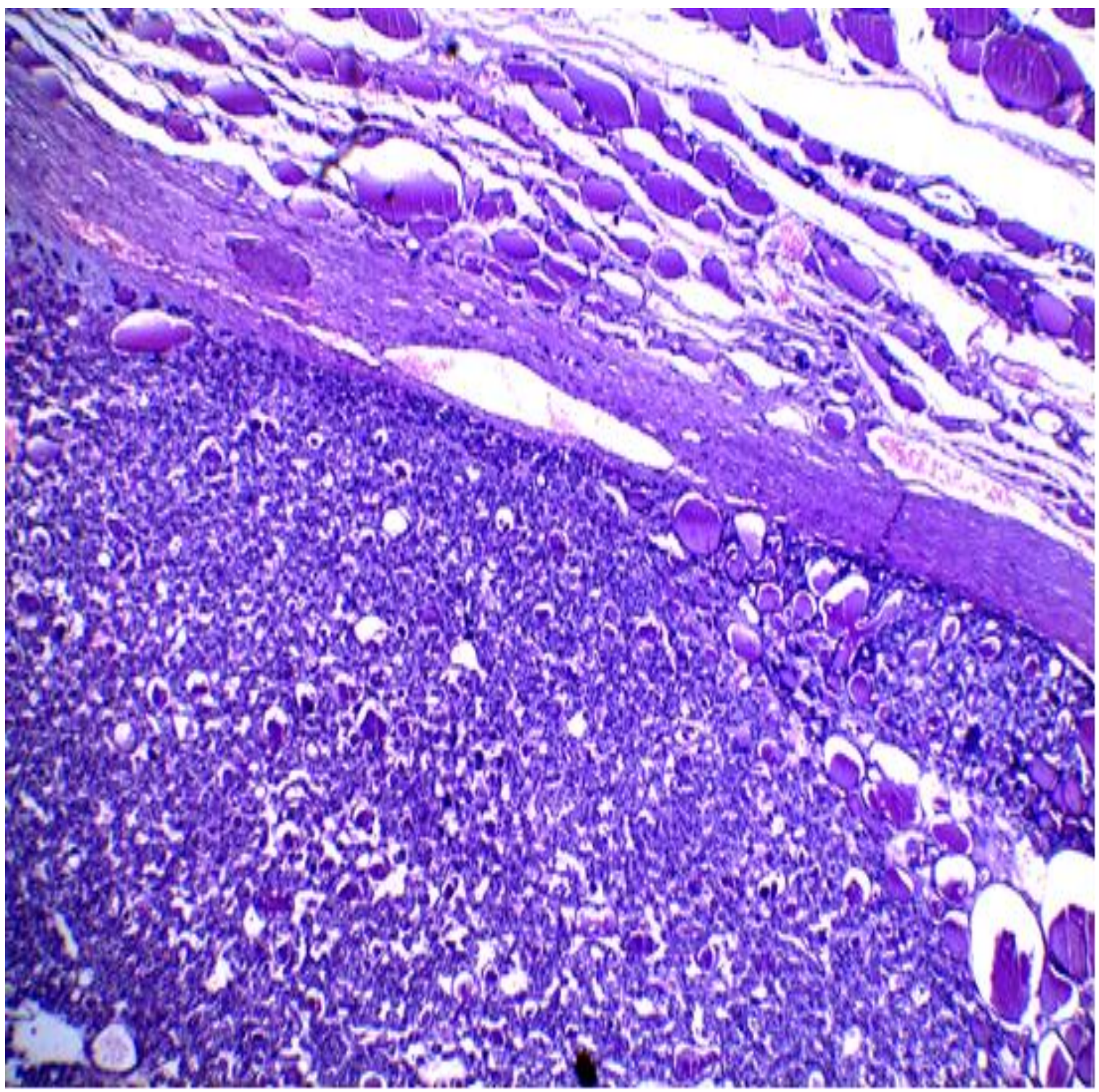


Fig.2 A case of papillary thyroid carcinoma with psammomatous calcification [H\&E, x200]

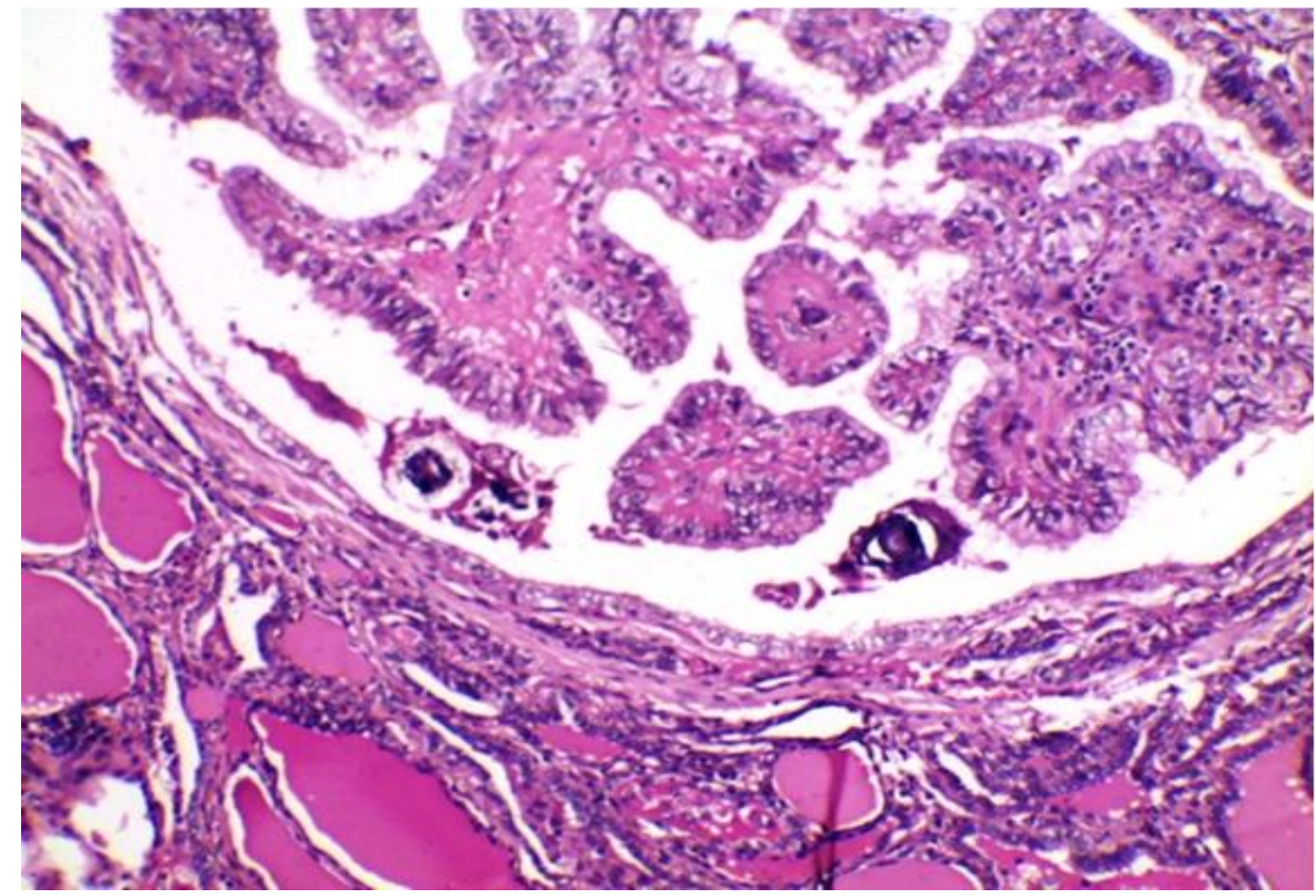

Fig.3 A case of insular carcinoma showed nests formed of small cells with round nuclei and indistinct cell borders surrounded with scattered micro-follicles containing dense colloid [H\&E, x200]

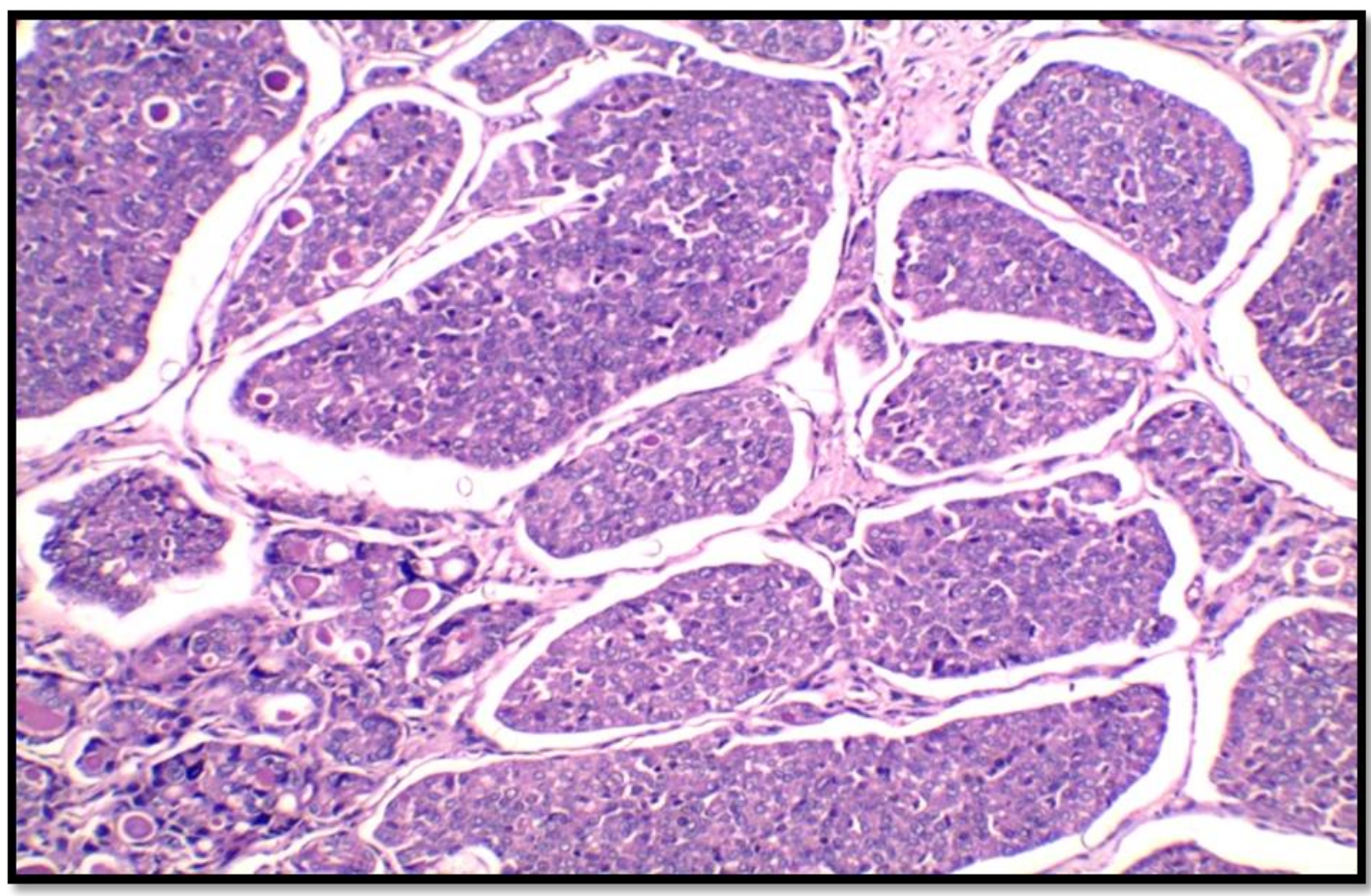


Fig.4 A case of Hurthle cell adenoma on a window of image analysis system showing mean nuclear area and perimeter

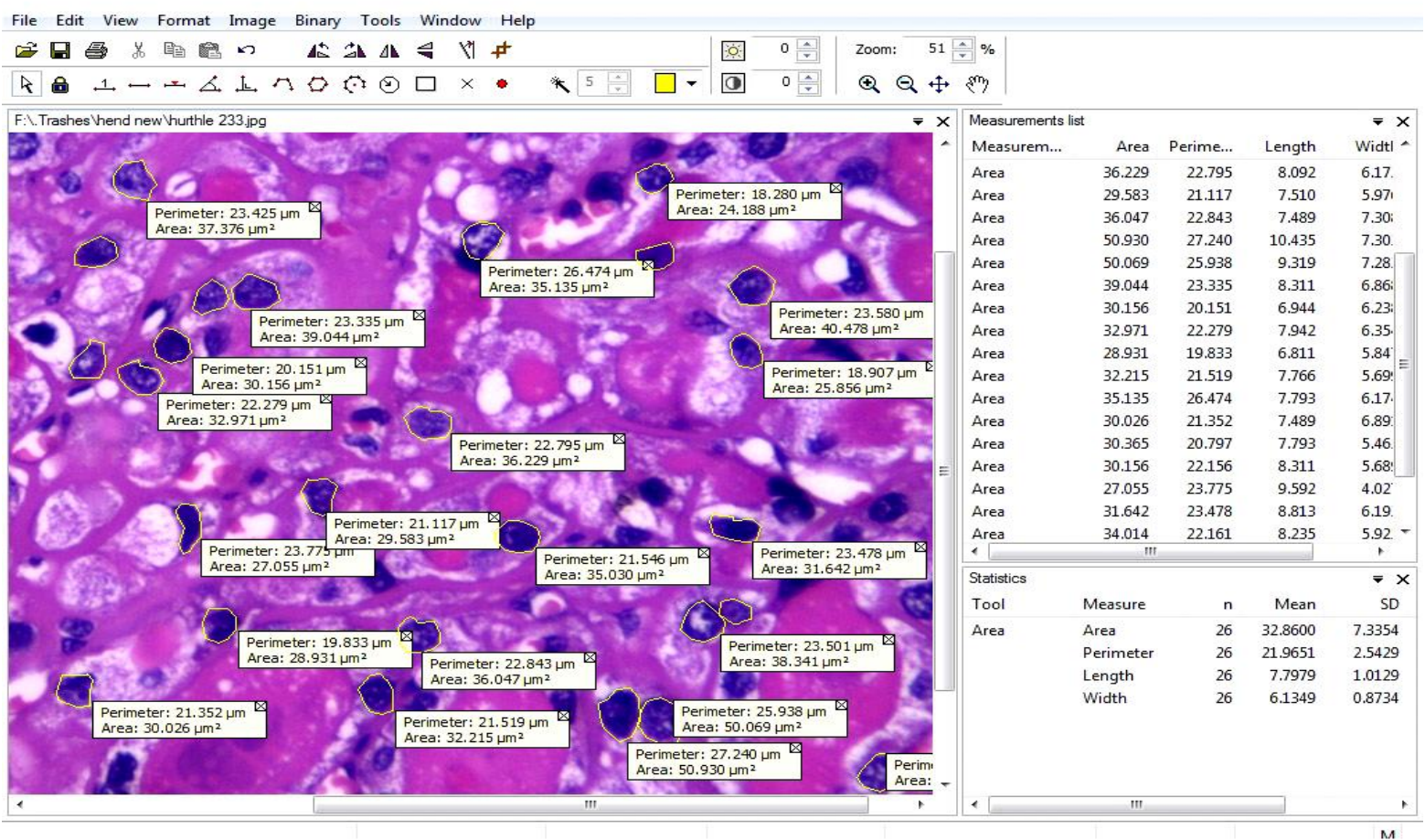

Fig.5 A case of FVPTC on a window of image analysis system showing mean nuclear area and perimeter

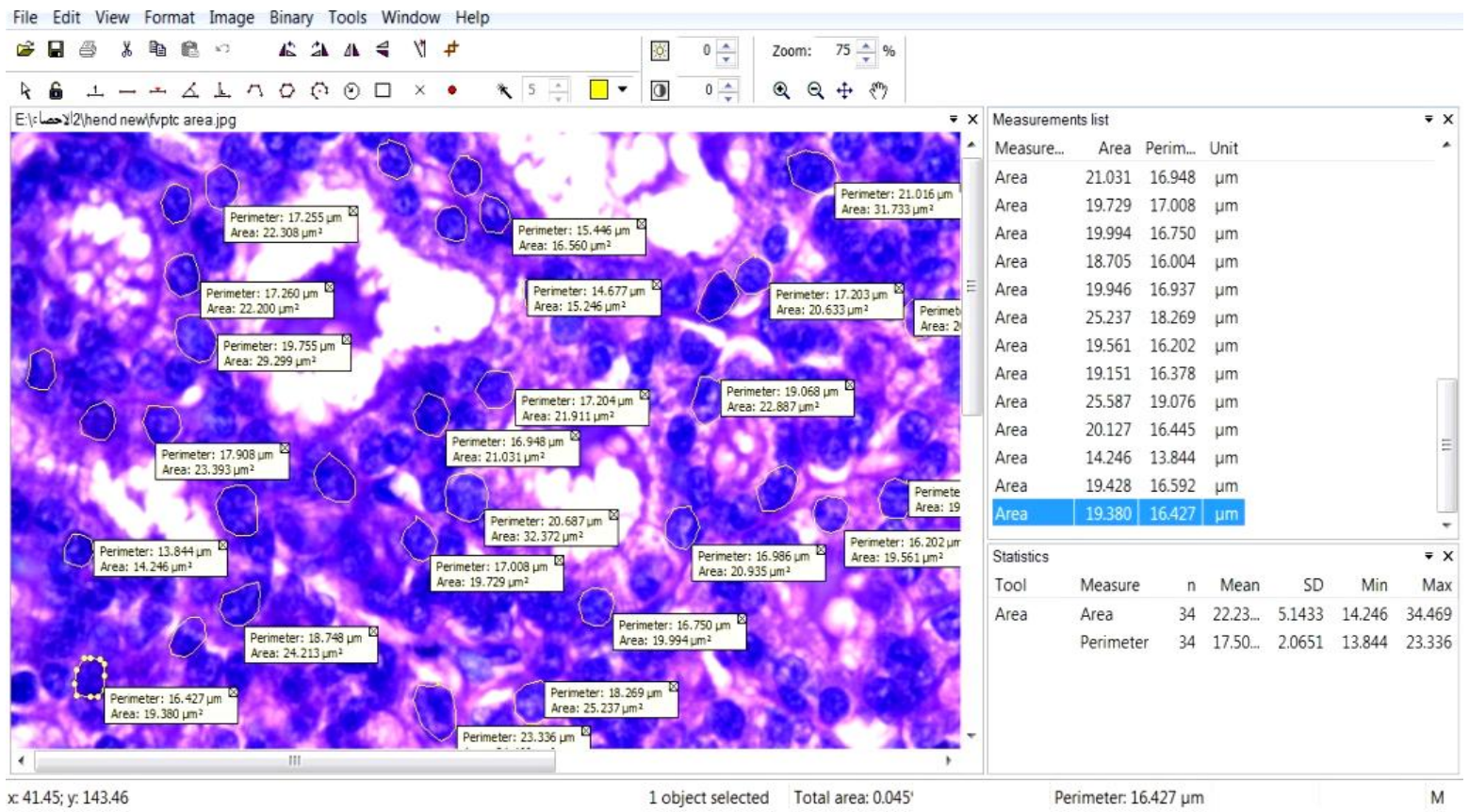


Fig.6 A case of follicular adenoma on a window of image analysis system showing measurement of the maximal nuclear diameter

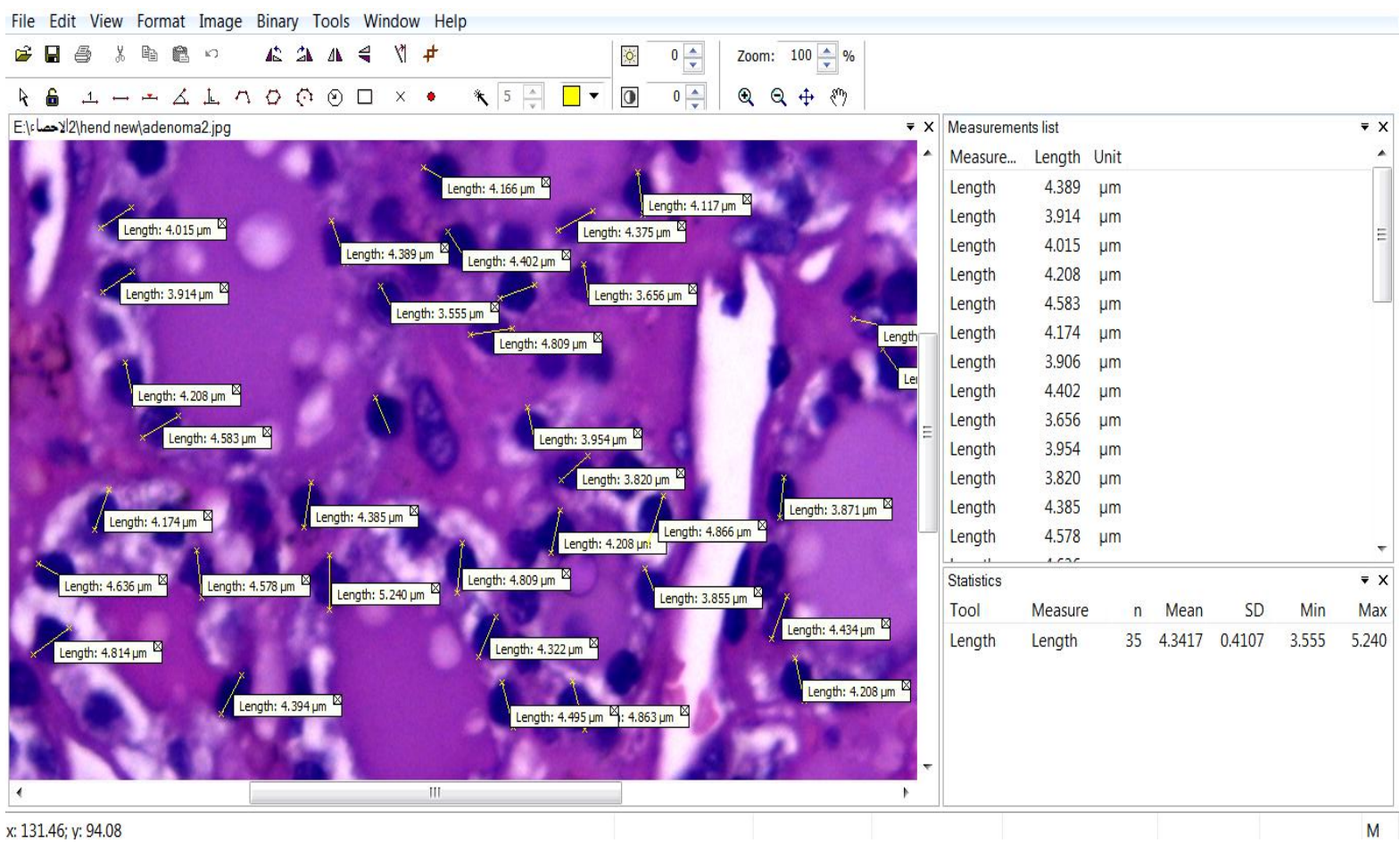

Fig.7 A case of insular carcinoma on a window of image analysis system showing measurement of the maximal nuclear diameter

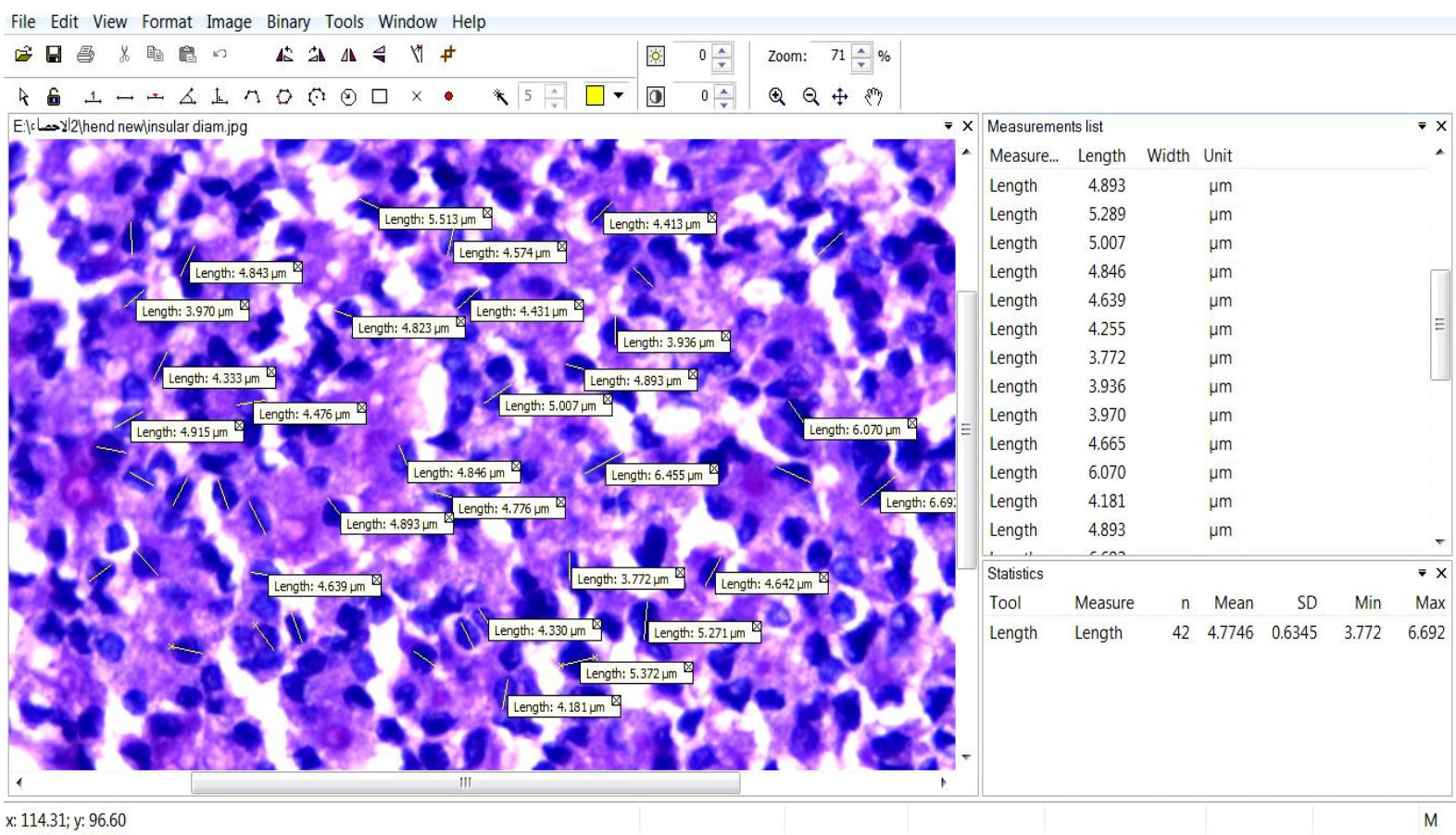

In a study conducted by Aiad et al., (2009), the nuclei of FVPTC were significantly larger 
than those of other follicular neoplasms (FA and FC), but in the current study follicular carcinoma demonstrated a higher MNA than that of FVPTC and follicular adenoma with a statistically significant correlation between them. Similarly, Wright et al., (1987) detected significant differences in MNAs and nuclear perimeters between Multinodular goiters and follicular and papillary neoplasms and significant differences between FAs and follicular and papillary carcinomas.

Regarding the nuclear perimeter in the studied benign cases, granulomatous thyroiditis was found to have the lowest nuclear perimeter (5.57 um) while Hurthle cell adenoma had the highest nuclear perimeter (21.96 um). Meanwhile, among the malignant cases, PDTC recorded the lowest nuclear perimeter (14.49 um), while anaplastic carcinoma cases were found to have the highest nuclear perimeter $(25.18 \mathrm{um})$ with a statistically significant correlation.

On comparison between follicular adenoma, follicular carcinoma and FVPTC in the current work, statistically significant correlation was found between them regarding nuclear perimeter indicating that it can be used for differentiation between these lesions.The $\mathrm{P}$ value was $0.014^{*}$ between follicular adenoma \& FVPTC and 0.001* between FA\&FC and $0.002 *$ between FVPTC $\& F C$.

On the contrary, Kaur and Jayaram, (1991) reported that nuclear features were not helpful in differentiation of follicular carcinomas from adenomas. Nagashima et al., (1998) evaluated variation in nuclear size by using NACV (nuclear area coefficient variation) and showed significant differences among follicular carcinomas, adenomas and adenomatous goiters.

In a study conducted by Dey and Saikia, (2011), nuclear perimeter of PDTC cases was
23.01 um which is higher than that of the current results (14.49 um), but the nuclear perimeter for follicular carcinoma was 25.63 which approximate that of the current study(22.00 um).

Wang et al., (2005) observed a very strong statistical difference between the morphometric high and low values of MNA and nuclear perimeter of FC and FA. Accordingly the suggestions of the current work agree with those of other authors who consider that the differential diagnosis between FC and FA could be based on nuclear characteristics, especially nuclear size and perimeter. If a suitable cut-off value for nuclear parameters is chosen, the computerized morphometric study may help to improve the accuracy of standard histopathological examination.

Regarding the maximal nuclear diameter (MND) in the studied benign cases, granulomatous thyroiditis was found to have the lowest MND (1.62um), while Hurthle cell adenoma recorded the highest MND measurement (5.59um) among benign studied cases.

The morphometric studies of the malignant thyroid cases showed also statistically significant differences. Thus among malignant cases medullary thyroid carcinoma was found to have the lowest nuclear diameter (2.15um) while anaplastic thyroid carcinoma had the highest diameter (8.03 um).

The differentiation between follicular adenoma, follicular carcinoma and FVPTC in the current work also revealed a statistically significant correlation between them regarding maximal nuclear diameter indicating that it can be used for differentiation between these lesions. The $\mathrm{P}$ value was $0.005^{*}$ between follicular adenoma\& FVPTC and $0.001^{*}$ between 
FA\&FC and it was0.001* between FVPTC $\&$ FC.

In a study conducted by Dey and Saikia, (2011), nuclear diameter of PDTC was 7.31 which is higher than that of the current results (4.77 um), but the nuclear diameter for follicular carcinoma was 7.66 which is near to the results of the current study (7.26 um). Besides, they did not detect any significant difference of various morphometric variables in the two groups of carcinomas and their data indicated that the nuclear morphometric variables of PDT Care similar as those of follicular carcinoma, while Priya and Sundaram, (2011) found that the mean nuclear diameter and the perimeter were higher in anaplastic carcinomas (10.78 um and $11.39 \mathrm{um}$ ) and were the least for follicular neoplasms (1.49 um and $2.97 \mathrm{um}$ ).

Dey and Saikia, (2011) mentioned that, nuclear morphometry data ofthe nuclear size and shape of PDTC and FC are essentially similar and it is not possible to differentiate these two entities with the help of image morphometric data.

However, Jankovic' et al., (2011) concluded that preoperative morphometry is a useful method in the differential diagnosis of thyroid carcinoma from benign lesions, and considered it as a complementary method to conventional cytodiagnostics.

Among benign thyroid lesions granulomatous thyroiditis had the lowest while Hurthle cell adenoma had the highest MNA, NP and MND with statistically significant values.

Among malignant thyroid lesions anaplastic carcinoma had the highest while PDTC and medullary carcinoma had the lowest morphometric measurements.

Statistically significant differences were found between follicular adenoma and follicular carcinoma as well as between follicular adenoma and FVPTC were found as regards MNA, NP and MND.

\section{Competing interests}

The authors declare that they have no competing interests.

\section{References}

Abdel Maksoud A, AbdElfattah GA, Amer RZ, et al., (2013): Evaluation of galectin-3, b-catenin, and nuclear morphometry in different thyroid lesions. Egypt J Pathol; 33:129-138.

Aiad HA, Abdou AG, Bashandy MA, et al., (2009) Computerized nuclear morphometry in the diagnosis of thyroid lesions with predominant follicular pattern. Ecancer; 3:1-13.

Bakr MH, Mourad M and Agina HA (2000): DNA ploidy, nuclear morphometry and Ki-67 proliferative index in the differentiation of thyroid follicular neoplasia. Egypt J Pathol; 20:117-124.

Buehler D, Hardin H, Shan W, et al., (2013) Expression of epithelial-mesenchymal transition regulators SNAI2 and TWIST1 in thyroid carcinomas. Modern pathology: an official journal of the United States and Canadian Academy of Pathology, Inc. 2013; 26(1): 54-61.

Cătană R, Boilă A, Borda A, Thyroid cancer profile in Mures County (Romania): a 20 years study, Rom $J$ MorpholEmbryol, 2012, 53(4):10071012

Colonna M, Bossard N, Guizard AV, Remontet L, Grosclaude P; le réseau FRANCIM, Descriptive epidemiology of thyroid cancer in France: incidence, mortality and survival, Ann.Endocrinol (Paris), 2010, 71(2):95-101. 
DeyPranab D, Saikia Uma Nahar (2011): Image Cytometry of Insular Carcinoma, Diagnostic Cytopathology; 40(2):188-9.

Gharib H, Papini E, Paschke R, Duick DS, Valcavi R, Hegedüs L, Vitti P; AACE/AME/ETA Task Force on Thyroid Nodules, American Association of Clinical Endocrinologists, Associazione Medici Endocrinologi, and European ThyroidAssociation Medical Guidelines for Clinical Practice for the Diagnosis and Management of Thyroid Nodules, EndocrPract, 2010, 16(Suppl 1):1-43.

Guerra A, Vincenzo D, Alfredo G, et al., (2013): Genetic mutations in the treatment of an plastic thyroid cancer: a systematic review. BMC Surgery; 13(Suppl 2):1-6.

Jankovic' SK, Andjelkovic' Z, Cerovic' S, et al., (2011). Thyrocyte morphomethric analysis significance in differential diagnosis of thyroid carcinoma. Vojnosanit Pregl; 68:669-675.

Kaur A and Jayaram G (1991): Thyroid tumours: cytomorphology of follicular neoplasms. DiagnCytopathol; 7:469-72.

Mokhtar N, Goda E and Adel E (2007): Cancer Pathology Registry 2003-2004, NCI-Egypt: the Department of Pathology, NCI.

Nagashima T, Suzuki M, Oshida M, et al., (1998): Morphometry in the cytological evaluation of thyroid follicular lesions. Cancer; 84:115-8.
Ozolins A, Narbuts Z, Strumfa I, et al., (2012): Immuno histochemical expression of HBME-1, E-cadherin, and CD56 in the differential diagnosis of thyroid nodules. Medicina (Kaunas); 48(10):507-514.

Priya SS, Sundaram S. Morphology to morphometry in cytological evaluation of thyroid lesions.J Cytol 2011; 28:98102.

Rossi ED, Straccia P, Palumbo M, et al., (2013): Diagnostic and prognostic role of HBME-1, galectin-3, and $\beta$-catenin in poorly differentiated and anaplastic thyroid carcinomas. Appl. Immunohistochem Mol. Morphol; 21:237-241.

Shih SR1, Chang YC, Li HY, Liau JY, Lee CY, Chen CM, Chang TC (2013). Preoperative prediction of papillary thyroid carcinoma prognosis with the assistance of computerized morphometry of cytology samples obtained by fine-needle aspiration: preliminary report. Head Neck. 2013. Jan; 35(1):28-34

Wang SL, Wu MT, Yang SF, et al., (2005): Computerized nuclear morphometry in thyroid follicular neoplasms. PatholInt; 55:703-706.

Wright RG, Castles $\mathrm{H}$ and Mortimer RH (1987). Morphometric analysis of thyroid cell aspirates. J ClinPathol; 40:443-445.

\section{How to cite this article:}

Hend S. A. Abo Safia, Samir N. Mina, Zeinab M. K. El-Guindy, Omnia M. K. Rizk and Dareen A. M. Ali. 2018. Nuclear Morphometric Study in Different Thyroid Lesions. Int.J.Curr.Microbiol.App.Sci. 7(09): 3483-3494. doi: https://doi.org/10.20546/ijcmas.2018.709.432 